Mal J Nutr 27(2): 221-231, 2021

\title{
Environmental enteric dysfunction, soil transmitted helminthiasis and stunting among 36- to 59-month-old children in Quezon Province, Philippines
}

\author{
Angelina R. Bustos ${ }^{1 *}$, Carmelita M. Rebancos ${ }^{2}$, Corazon VC. Barba ${ }^{1}$, Victorio B. \\ Molina $^{3}$, Merlyne M. Paunlagui ${ }^{4} \&$ Nancy A. Tandang 5 \\ ${ }^{1}$ Institute of Human Nutrition and Food, College of Human Ecology, University \\ of the Philippines Los Baños, Philippines; ${ }^{2}$ School of Environmental Science and \\ Management, University of the Philippines Los Baños, Philippines; ${ }^{3}$ Department of \\ Environmental and Occupational Health, College of Public Health, University of the \\ Philippines Manila, Philippines; ${ }^{4}$ Center for Strategic Planning and Policy Studies, \\ College of Public Affairs and Development, University of the Philippines Los Baños, \\ Philippines; ${ }^{5}$ Institute of Statistics, College of Arts and Sciences, University of the \\ Philippines Los Baños, Philippines
}

\begin{abstract}
Introduction: Environmental enteric dysfunction (EED) is relevant in public health as it is a potential cause of child stunting. In the Philippines, stunting affects $33.4 \%$ of children in 2015. As of date, no local studies on EED exist. This study primarily aimed to determine the prevalence of EED, soil transmitted helminthiasis (STH) and stunting; and their relationships. Methods: A cross-sectional study was conducted among 120 children aged 36-59 months old in Quezon Province, Philippines. EED was assessed via glucose hydrogen breath test with a cut-off of $\geq 20$ ppm over baseline by 90 minutes suggestive of small intestinal bacterial overgrowth (SIBO), a biomarker of EED. Kato Katz Technique was used to determine STH. Stunting was determined using the 2006 World Health Organization Child Growth Standards. Descriptive and correlation analyses of data were done at $10 \%$ level of significance. The study received approval from the National Ethics Committee of PCHRD-DOST, Philippines. Results: Data on expired hydrogen level of $<20 \mathrm{ppm}$ were documented. The prevalence of STH among children were 38.1\% for Ascaris lumbricodes, $15.3 \%$ for Trichuris trichiura, and $1.7 \%$ for hookworm infections. A high rate of stunting at $40.0 \%$ was observed. There was a significant positive association between stunting and the presence of Ascaris ( $p=0.01$ ). Conclusion: There was no case of EED detected in the study. The severity of stunting was high at $40.0 \%$. Among the STH, the prevalence of $38.1 \%$ children having Ascaris lumbricodes was alarming in terms of morbidity control. Nutrition interventions including WASH practices and the use of anthelminthic drugs need to be intensified to address stunting and STH.
\end{abstract}

Keywords: Environmental enteric dysfunction, stunting, small intestinal bacterial overgrowth, soil transmitted helminthiasis

\footnotetext{
*Corresponding author: Dr. Angelina R. Bustos Institute of Human Nutrition and Food, College of Human Ecology, University of the Philippines Los Baños, Laguna, Philippines

Tel: (63)917-5151-232 E-mail: arbustos@up.edu.ph

doi: https://doi.org/10.31246/mjn-2020-0043
} 


\section{INTRODUCTION}

Stunting among children younger than 5 years is a major global health priority that has gained international attention because of its significant consequences on health and development. In the Philippines, stunting has remained unchanged over the years, affecting $33.4 \%$ children in 2015 (FNRI-DOST, 2016). Recognising that the primary drivers of undernutrition are inadequate dietary intake and recurrent infection, strategies to prevent and/or to address undernutrition are focused on dietary solutions, as well as water, sanitation and hygiene (WASH) interventions. However, both interventions have small to moderate impacts on linear growth. Dietary interventions impact linear growth from only 0.12 to 0.28 in terms of length-for-age $\mathrm{Z}$-score (Dewey \& Adu-Afarwuah, 2008), while WASH interventions implemented with 99\% coverage would reduce stunting prevalence by only $2.4 \%$ (Bhutta et al., 2008). This indicates that the cause of stunting transcends beyond dietary inadequacy and infections. The pathogenesis of stunting is poorly understood (Owino et al., 2016) and implicates that a subclinical disorder of the small intestine known as environmental enteropathy (EE) or environmental enteric dysfunction (EED) may have caused poor linear growth (Humphrey, 2009; Owino et al., 2016).

EED is a condition when there are abnormalities in the intestinal mucosa and is characterised by the presence of bacterial overgrowth in the small intestine. Small intestinal bacterial overgrowth (SIBO) contributes to the pathogenesis of EED as overgrowth has been associated with EED domains such as intestinal inflammation and micronutrient malabsorption (Harper et al., 2018; Donowitz et al., 2016; Vonaesch et al., 2018). EED is found at a high prevalence among stunted children living under poor sanitary conditions and is pandemic in developing countries with limited resources (Owino et al., 2016).

The impact of helminth colonisation on EED has not been well studied, but considering that the prevalence of intestinal soil transmitted helminthiasis (STH) infections is high, this study attempted to establish an association between STH and EED. STH infections remain a public health problem in many areas in the Philippines where challenges related to water, sanitation and hygiene continue to be experienced. Specifically, the prevalence of STH in the Philippines was noted at $27.7 \%$ for $A$. lumbricoides, $31.3 \%$ for $T$. trichiura, and $13.3 \%$ for hookworm (Soares Magalhães, 2015). The estimated prevalence of STH in the Philippines in school age children and preschool age children have not satisfied the targets of $<20 \%$ cumulative prevalence and zero heavy intensity STH recommended by the World Health Organization (WHO) in order to achieve morbidity control (Belizario et al., 2015).

As of date, no local studies are available that looked into the occurrence of EED in the Philippines. Hence, this study aimed to determine the prevalence of EED, STH and stunting among 36to 59-month-old children; and their relationships. It also aimed to identify determinants of stunting among the study children.

\section{MATERIALS AND METHODS}

A stratified multi-stage sampling was employed in this cross-sectional study among 36- to 59-month old children in the province of Quezon, Philippines, where stunting prevalence among children $<5$ years old was highest in the CALABARZON region at 33.9\% (FNRIDOST, 2016). This group of children was 
selected because of their cognitive, social and motor skills that enabled them to comply with research protocols. All apparently healthy children who had no feeding problem and inborn/congenital/ severe illness; who were not suffering from disease at the time of recruitment; who were not taking antibiotics for the last four weeks; residents in the barangay or municipality for the past six months; and with signed informed consent were included in the study.

To select the study areas, all municipalities in the Province were grouped into two strata, namely: low- and high-income municipalities. Per stratum, one municipality was randomly selected to represent the low ( $5^{\text {th }}$ class) and high ( $1^{\text {st }}$ class) income municipalities. Using the list of children 0-71 months old obtained from the Municipal Nutrition Action Officers, children aged 36-59 months from all qualified barangays were constructed as the sampling frame. The required sample size was estimated based on the prevalence of stunting (33.9\%) among children in Quezon and the total number $(124,411)$ of children aged 36-59 months in Quezon with a sampling error of $8 \%$, level of confidence of $90 \%$, and a design effect of 1.3 . A total of 120 children was computed and were randomly drawn from the master list obtained from the Municipal Nutrition Action Officers. A randomly selected replacement was considered in case of disapproval from mothers to participate, decided to terminate participation in any stage of the study, or failed to conform with the preconditions for hydrogen breath testing.

The mothers or caregivers of the selected children were invited for a meeting to explain the nature and purpose of the study, as well as the study protocols. Assistance from the municipal and barangay officials, health and nutrition workers, and day-care teachers who were oriented on the study were tapped to encourage participation of the respondents.

Glucose was used as the test substance for the diagnosis of SIBO using the Hydrogen Breath Test Sleuth by Breathe EZ Systems, Inc. In this study, EED was defined with SIBO as the biomarker for the pathophysiological changes of malabsorption and intestinal inflammation characterising EED. Study children were examined by a paediatrician before enrolment to ensure that they were physically/ medically fit for the Glucose Hydrogen Breath Test. Demonstration on how to breath using disposable mouthpiece and how to release expired air to the breath analyser was also conducted by the municipal nurse or the researcher. Mothers/caregivers were advised not to give their children any slowly digested foods, any fibre supplements and laxatives for 24 hours prior to the test, and to fast for 8-12 hours before the procedure. On the day of assessment, mouth rinse was first administered to children in order to avoid the possibility of an early peak in hydrogen associated with the action of bacteria in the mouth on the carbohydrates used in the test. Children were instructed not to swallow the mouthwash. The test began with the collection of a basal expired air (fasting sample). Baseline breath hydrogen was measured by letting children take a deep breath of air and expired into the mouthpiece until all the air was out of the lungs. The presence of bacterial overgrowth was ruled out before performing the glucose breath test. Children who were eligible but with a baseline expiratory breath of $>10$ ppm, which is indicative of bacterial overgrowth, were excluded from the study. Glucose was then administered orally. A glucose load of $1.75 \mathrm{~g} / \mathrm{kg}$ body weight up to a maximum of $75 \mathrm{~g}$ (Harriet Lane Handbook, 2017) dissolved in $10 \mathrm{ml} / \mathrm{kg}$ body weight up to a maximum 
of $250 \mathrm{ml}$ (Eisenmann et al., 2008) was appropriate for children. Using this as reference, the glucose drink (Medic orange, glucose test beverage) formulated by the Medic Diagnostic Laboratory in Pasig City, Philippines was used as the test substance. Samples of expired air were measured at 30-, 60and 90 minutes after glucose load. The 2017 North American Consensus was adopted such that the length of glucose testing was limited to two hours; and the diagnostic criteria used was a rise in expired hydrogen of $\geq 20 \mathrm{ppm}$ from baseline by 90 minutes as the ideal criterion for a positive test to suggest the presence of SIBO (Rezaie et al., 2017).

Height measurements were carried out following the standard procedures and recommended equipment as prescribed in the National Health and Nutrition Examination Survey (NHANES) Anthropometry Procedures Manual (CDC, 2013). Microtoise was used to measure the height of children in centimeters. Two measurements of height were taken and recorded to the nearest $0.1 \mathrm{~cm}$. A third reading was required when the two measurements were beyond the acceptable limits $(0.5 \mathrm{~cm}$ for height). Age in months of each child was also collected to enable the determination of nutritional status. The corresponding $\mathrm{Z}$-scores were computed using the 2006 WHO Child Growth Standards (CGS) software to determine the nutritional status of the children. Children with $Z$-scores $<-2$ standard deviation $(S D)$ for height-for-age were classified as stunted.

The collection, packaging, storage and transport of faecal samples followed the procedures prescribed by the Department of Parasitology, University of the Philippines, Manila, where parasitological assessment was done. Each mother/caregiver received an improvised paper triangle lined with wax paper instead of a plastic cup, wooden stick and re-sealable plastic bag for one stool specimen of each child. A demonstration of stool collection was done in such a way that thumb-size stool was to be placed in the paper triangle using the wooden stick, then folding the paper to secure the specimen and putting it in a re-sealable plastic bag. The respondents were informed of the schedule of collection either at a specified venue or via house visits. Immediately after submission, sealed and labelled specimens were placed in an insulated box (styrofoam box) packed with ice and transported to the laboratory within 24 hours after collection. Parasitological assessment utilised the Kato-Katz technique following the WHO's Bench Aids for the Diagnosis of Intestinal Parasites (WHO, 1994). Microscopic reading of the slides was done by the microscopist to determine the prevalence of individual STH species, namely: Ascaris lumbricodes, Trichuris trichiura and hookworm.

Data entry was done in Microsoft Excel and analysed using the Statistical Package for Social Sciences (SPSS) software version 23. Data cleaning for inconsistencies, errors, double entry were performed before data analysis.

The profile and distributional characteristics of the subjects were described using appropriate descriptive statistics and by constructing percent distributions. Correlation analysis was done to determine the significant associations between variables. In particular, point biserial correlation coefficient was used for correlating dichotomous variables with quantitative data, while Cramer's $V$ coefficient (based on chi-square) was used for nominal variables. Significant factors were determined at $10 \%$ level of significance.

This research received ethical approval from the National Ethics Committee of the Philippine Council for Health Research and Development of the 
Table 1. Distribution of nutritional status in children 36-59 months in Quezon Province, Philippines based on height-for-age Z-score (HAZ)

\begin{tabular}{lc}
\hline $\begin{array}{c}\text { Nutritional status based on Height-for-age } Z \text {-score } \\
(H A Z)(n=120)\end{array}$ & Magnitude (\%) \\
\hline Severely stunted $(<-3 S D)$ & 7.5 \\
Moderately stunted $(<-2 S D$ to $-3 S D)$ & 32.5 \\
Normal $(-2 S D$ to $+2 S D)$ & 60.0 \\
\hline
\end{tabular}

Department of Science and Technology (PCHRD-DOST), Philippines.

\section{RESULTS}

Overall, the prevalence of stunting in the study area was $40.0 \%$, with $7.5 \%$ children classified as severely stunted and $32.5 \%$ moderately stunted (Table $1)$. With reference to the WHO cutoff points (WHO, 1995), the severity of stunting in this study was very high at $40.0 \%$ magnitude. This prevalence was higher compared with the 2015 national prevalence of $33.4 \%$ for stunting, but consistent with Quezon Province at $40.0 \%$ based on the FNRI National
Nutrition Survey in 2015 (DOST-FNRI, 2016).

Results of the parasitological assessment revealed that Ascaris lumbricodes infections were seen in $38.1 \%$ of the study children; Trichuris trichiura infections were seen in 15.3\% of the study children; and for hookworm infections, a prevalence of $1.7 \%$ was observed.

Figure 1 shows the expired hydrogen of 120 children from baseline and by 30-, 60-, and 90-minutes after ingestion of glucose. By definition, a positive test to suggest the presence of EED is a rise of $\geq 20 \mathrm{ppm}$ from baseline in breath

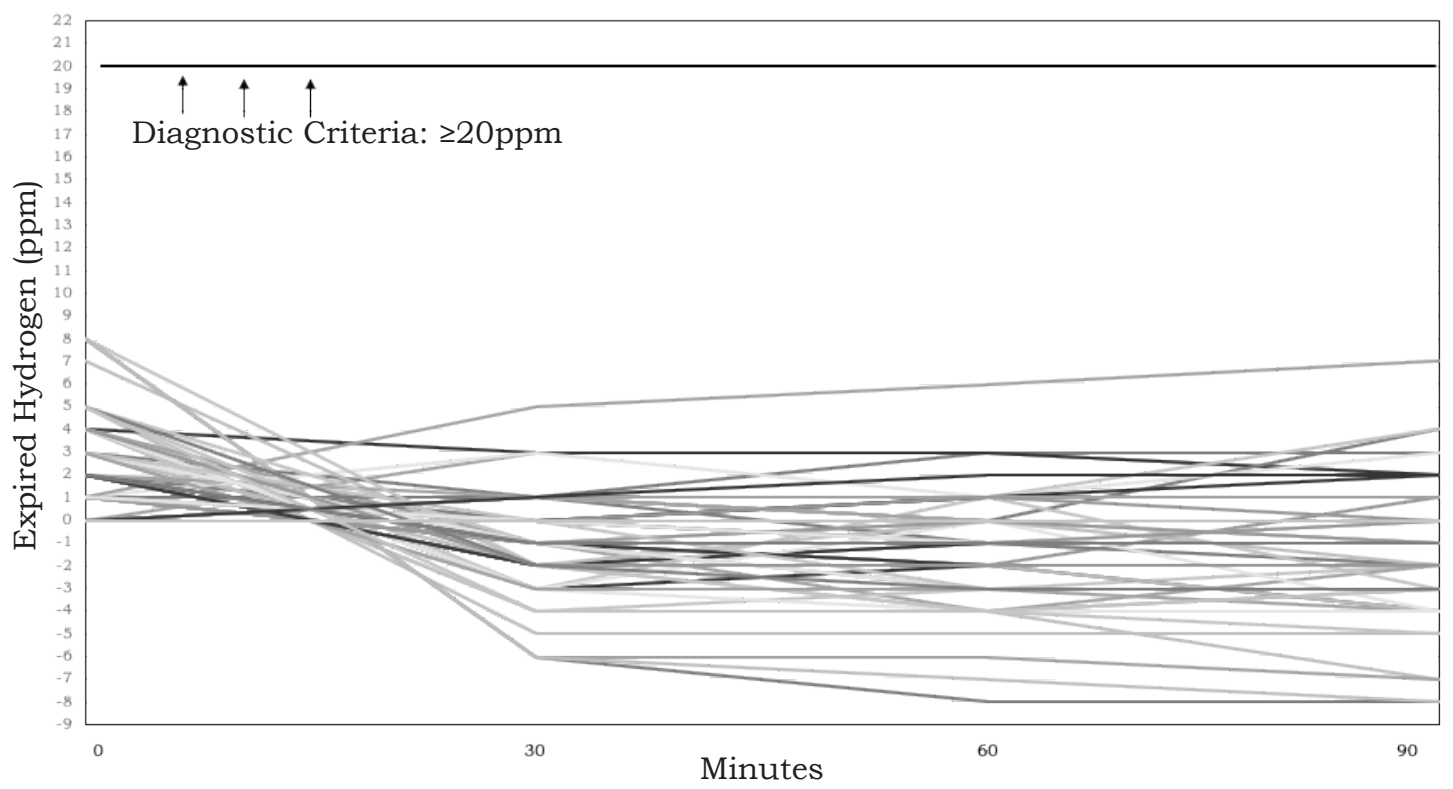

Figure 1. Expired hydrogen of 120 children aged 36-59 months at baseline, 30-, 60-, and 90-minutes after ingestion of glucose 
Table 2. Measures of the associations between stunting and socio-demographic-economic variables, food intake, feeding and health practices, WASH variables, and STH in children 3659 months in Quezon Province, Philippines

\begin{tabular}{lll}
\hline & \multicolumn{2}{c}{ Stunting } \\
\cline { 2 - 3 } Variables & Correlation coefficient & $p$-value \\
\hline Socio-demographic-economic variables & & \\
Household size & $0.114^{\mathrm{a}}$ & 0.22 \\
Household income & $0.118^{\mathrm{a}}$ & 0.20 \\
Nutrient intake & & \\
Energy & $-0.088^{\mathrm{a}}$ & 0.34 \\
Protein & $-0.164^{\mathrm{a}}$ & $0.07^{*}$ \\
Calcium & $-0.176^{\mathrm{a}}$ & $0.05^{*}$ \\
Phosphorus & $-0.279^{\mathrm{a}}$ & $<0.001^{* * *}$ \\
Iron & $-0.093^{\mathrm{a}}$ & 0.31 \\
Vitamin A & $-0.198^{\mathrm{a}}$ & $0.03^{* *}$ \\
Riboflavin & $-0.273^{\mathrm{a}}$ & $0.00^{* * *}$ \\
Niacin & $-0.025^{\mathrm{a}}$ & 0.77 \\
Feeding and health practices & & \\
Breastfeeding after birth & $0.006^{\mathrm{b}}$ & 0.95 \\
End of exclusive breastfeeding & $0.325^{\mathrm{b}}$ & $<0.001^{* * *}$ \\
Full immunisation & $0.185^{\mathrm{b}}$ & $0.04^{* *}$ \\
WASH variables & & \\
Type of drinking water & $0.185^{\mathrm{b}}$ & $0.04^{* *}$ \\
Drinking water service level & $0.292^{\mathrm{b}}$ & $0.01^{* *}$ \\
Toilet classification & $0.170^{\mathrm{b}}$ & $0.06^{*}$ \\
Toilet service level & $0.181^{\mathrm{b}}$ & 0.14 \\
Hand washing service level & $0.022^{\mathrm{b}}$ & 0.81 \\
Appropriate hand washing techniques & $0.150^{\mathrm{b}}$ & 0.10 \\
Soil transmitted helminthiasis & & $0.01^{* *}$ \\
Ascaris presence & $0.252^{\mathrm{b}}$ \\
Trichuris presence & $0.136^{\mathrm{b}}$ & 0.77 \\
Hookworm presence & $0.027^{\mathrm{b}}$ & \\
\hline
\end{tabular}

${ }^{a}$ correlation coefficient using Point Biserial

${ }^{\mathrm{b}}$ correlation coefficient using Cramer's V

*significant at $p$-value $<0.10$

**significant at $p$-value $<0.05$

$* * *$ significant at $p$-value $<0.01$

hydrogen by 90 minutes (Rezaie et al., 2017). In this study, the mean expired hydrogen concentration at 90 minutes from baseline was $0.73 \mathrm{ppm}$ (Range: 0,8). Results showed that children demonstrated no increase in breath hydrogen greater than the diagnostic criteria of $20 \mathrm{ppm}$. Hence, there was no case of EED detected in this study.
Correlation analysis is presented in Table 2. Results showed that stunting was significantly and negatively associated with nutrient intakes of protein $(p=0.07)$, calcium $(p=0.05)$, phosphorous $(p<0.001)$, vitamin A $(p<0.001)$, and riboflavin $(p=0.00)$. Moreover, stunting was found to be significantly associated with the age of 
Table 3. Summary of significantly associated factors with stunted or not stunted children aged 36-59 months in Quezon Province, Philippines.

\begin{tabular}{|c|c|c|}
\hline \multirow{2}{*}{ Variables } & \multicolumn{2}{|c|}{ Stunting } \\
\hline & Not Stunted & Stunted \\
\hline \multicolumn{3}{|l|}{ Nutrients $^{\dagger}$ (Mean Percent EAR) } \\
\hline Protein & 220.6 & 197.0 \\
\hline Calcium & 122.0 & 94.7 \\
\hline Phosphorus & 150.1 & 119.4 \\
\hline Vitamin A & 154.5 & 118.7 \\
\hline Riboflavin & 228.2 & 163.5 \\
\hline \multicolumn{3}{|c|}{ End of exclusive breastfeeding ${ }^{\ddagger}(\%)$} \\
\hline$<6$ months & 65.1 & 34.9 \\
\hline$\geq 6$ months & 46.9 & 53.1 \\
\hline \multicolumn{3}{|l|}{ Immunisation $^{\ddagger}(\%)$} \\
\hline Fully immunised & 62.7 & 37.3 \\
\hline Incomplete immunisation & 30.0 & 70.0 \\
\hline \multicolumn{3}{|c|}{ Classification of drinking water ${ }^{\ddagger}(\%)$} \\
\hline Improved & 68.2 & 31.8 \\
\hline Unimproved & 50.0 & 50.0 \\
\hline \multicolumn{3}{|c|}{ Drinking water service level ${ }^{\ddagger}(\%)$} \\
\hline Basic & 70.7 & 29.3 \\
\hline Unimproved & 33.3 & 66.7 \\
\hline \multicolumn{3}{|l|}{ Toilet classification ${ }^{\ddagger}(\%)$} \\
\hline Improved & 61.7 & 20.0 \\
\hline Unimproved & 38.3 & 80.0 \\
\hline \multicolumn{3}{|c|}{ Soil transmitted helminthiasis ${ }^{\ddagger}(\%)$} \\
\hline Positive for Ascaris & 44.4 & 55.6 \\
\hline Negative for Ascaris & 69.9 & 30.1 \\
\hline
\end{tabular}

${ }^{+}$Comparison using $t$-test for independent samples

${ }^{\ddagger}$ Comparison using chi-square test

child when exclusive breastfeeding was stopped $(p<0.001)$, full immunisation $(p=0.04)$, type of drinking water $(p=0.04)$, drinking water service level $(p=0.01)$, and toilet classification $(p=0.06)$. With $\mathrm{STH}$, there was a significant positive association between stunting and the presence of Ascaris ( $p=0.01)$.

The summary of significantly associated variables with stunting or no stunting is shown in Table 3. The mean estimated average requirement (EAR) for nutrients was higher in children who were not stunted compared to those who were stunted. The proportion of children who were not stunted were higher for those who were exclusively breastfed just under six months (65.1\%) and fully immunised (62.7\%). Higher proportion of children who were not stunted used improved drinking water $(68.2 \%)$, basic water service level $(70.7 \%)$, improved toilet facilities $(61.7 \%)$, and practised appropriate hand washing techniques $(67.9 \%)$. For those who used unimproved toilet facilities, more children were 
stunted $(80.0 \%)$ than those who were not $(38.3 \%)$. The percentage of children found positive for Ascaris and stunted was higher $(55.6 \%)$ than those who were not stunted (44.4\%).

\section{DISCUSSION}

EED is becoming relevant in public health as it is a potential cause of child stunting. This cross-sectional study was conducted among 120 children aged 36-59 months old in Quezon Province, Philippines. It aimed to determine the prevalence of stunting, STH and EED; and their relationships. EED was assessed via glucose hydrogen breath test with a cut-off of $\geq 20$ ppm over baseline by 90 minutes suggestive of SIBO, a biomarker of EED.

Stunting remained a public health problem in the study area with a prevalence of $40 \%$. A higher proportion of stunted children were using unimproved drinking water service level (66.7\%) and unimproved toilet (80.0\%). Similar patterns were observed in the study of Danaei et al. (2016) which highlighted that environmental factors, particularly unimproved sanitation, is attributable to 7.2 million cases of stunting worldwide. It also presented that environmental risk factors such as poor water quality, poor sanitary conditions, among others have the second largest impact on stunting globally. A cross-sectional study in Indonesia also highlighted that the chances of stunting was three times higher among children in households with untreated water and unimproved latrine (Torlesse et al., 2016).

For soil transmitted helminthiasis, results showed that the prevalence of children having Ascaris lumbricodes was $38.1 \%$, which is considered alarming in terms of morbidity control based on the WHO's recommended cutoff of $<20 \%$ cumulative prevalence. In addition, Trichuris trichiura and hookworm infections were observed in $15.3 \%$ and $1.7 \%$ children, respectively. A cross-sectional study in Argentina among school age children showed a strong association between unimproved sanitation and unimproved drinking water with the presence of STH infection (Echasu, 2017). A meta-analysis of more than 40,000 studies (Strunz, 2015) further established the link between WASH factors and the presence of STH. It was estimated that an increase of 10,000 epg egg count of A. Lumbricoides will increase the odds of having stunting by $47 \%$ among children and adolescents (Jardim-Botelho et al., 2008). Pathogen colonisation may promote chronic inflammation and induce changes to intestinal microbiota, contributing to stunting and EED (Humphrey, 2009; Owino et al., 2016; Watanabe \& Petri, 2016; Gilmartin \& Petri, 2016; Harper et al., 2018). Among the pathophysiological changes underlying EED, the study of Harper et al. in 2018 found strong evidence supporting the pathway between intestinal inflammation and stunting. Hence, further analysis of pathogeninduced changes to the intestinal microbiota as a pathway leading to stunting needs to be investigated (Owino et al., 2016).

In this study, no case of EED was detected. Previous studies revealed that EED characterised by elevated expired hydrogen frequently occurs in developing areas with poor sanitation and hygiene (Korpe \& Petri, 2012; Prendergast \& Kelly, 2016), as well as limited public health resources, in association with microbial and parasitic contamination of food and water (Owino et al., 2016). Pereira et al. (1991) investigated SIBO in a cohort of 340 children under the age of 5 years in rural Burma (Myanmar) and detected SIBO in $27.2 \%$ children. In the study of Dos Reis et al. (2007) among 5 to 11 years old in Brazil, bacterial 
overgrowth was diagnosed in 18 (37.5\%) of the 48 slum dwelling children and in only one $(2.1 \%)$ of the 48 children in the control group. The homes of these slum dwelling children did not have running water or a sewerage system compared with the control group. Lin et al. (2013) supported these results in assessing the relationship of faecal environmental contamination and environmental enteropathy among children living in different levels of household environmental cleanliness across rural Bangladesh.

The absence of EED in this study was probably due to a better environmental condition of the study households compared with the above mentioned literatures. Specifically, majority of the households in the study areas had access to: (1) improved drinking water (55\%); (2) improved sanitation (60.8\%); and (3) availability of water (99.2\%) and soap (70\%) for hand washing. Only $11.7 \%$ of the households had earth floor material and only $39.2 \%$ raised animals.

Several limitations can be identified in the present study. The crosssectional design of this study did not allow any inference with regards to causal relationships. Similar to the findings of Donowitz et al. (2016), nondetection of EED in this study might be due to the limitation of cross-sectional analysis which only detects children with SIBO at the time of testing and may have missed children who have had recent or prolonged SIBO in their lifetime. Furthermore, the study is only a representative of one Province and the results therefore cannot be generalised for the whole population of the Philippines. Regardless of these limitations, to our knowledge, this was the first study on EED among children in the country. In addition, helminth colonisation on EED has not been well studied, thus the study was an attempt to establish an association between STH and EED.

\section{CONCLUSION}

The study revealed that there was no prevalence of EED detected among 36to 59-month-old children in Quezon Province. The prevalence of STH among children were $38.1 \%$ for Ascaris lumbricodes, $15.3 \%$ for Trichuris trichiura, and $1.7 \%$ for hookworm infections. Stunting prevalence was recorded at $40 \%$. Nutrition interventions together with the use of anthelminthic drugs, provision of clean water, environmental sanitation, and promotion of hygiene practices must be intensified to address problems on stunting and STH. This study revealed trends that warrants further epidemiological studies. The Hydrogen Breath Test employed can be adapted for a case control study with stunted subjects in areas with poor environmental conditions.

\section{Acknowledgement}

The team would like to extend their gratitude to the Governor and Municipal Mayors of Quezon Province; and Provincial and Municipal Nutrition Offices for their assistance and support during the conduct of the study. This work was supported by the Accelerated Science and Technology Human Resource Development Program (ASTHDRP) of the Department of Science and Technology (DOST), Philippines, The Neys van Hoogstraten Foundation (NHF) of The Hague, The Netherlands, and the Commission on Higher Education (CHED), Philippines.

\section{Authors' contributions}

ARB, principal investigator, conceptualised and designed the study, conducted data collection and analysis, prepared the manuscript; CVCB, VBM and MMP reviewed and provided technical inputs on the study design, data analysis and manuscript; NAT, provided technical inputs on the study and sampling design, data analysis and interpretation, and reviewed the manuscript.

\section{Conflict of interest}

The authors declare no potential conflicts of interest with respect to the research, authorship, and/or publication of this article. 


\section{References}

Belizario VY, Liwanag HJC, Naig JRA, Chua PLC, Madamba MI, \& Dahildahil RO (2015). Parasitological and nutritional status of schoolage and preschool-age children in four villages in Southern Leyte, Philippines: Lessons for monitoring the outcome of Community-Led Total Sanitation. Acta tropica $141(\mathrm{Pt} \mathrm{A}): 16-$ 24. https://doi.org/10.1016/j.actatropica. 2014.09.008.

Bhutta ZA, Ahmed T, Black RE, Cousens S, Dewey K, Giugliani E, Haider BA, Kirkwood B, Morris SS, Sachdev HPS, Shekar M \& Maternal and Child Undernutrition Study Group (2008). Maternal and Child Undernutrition 3. What works? Interventions for maternal and child undernutrition and survival. Lancet (London, England) 371(9610):417-440. https://doi. org/10.1016/S0140-6736(07)61693-6.

CDC (2013). National Health and Nutrition Examination Survey (NHANES) Anthropometry Procedures Manual, USA.

Dewey KG \& Adu-Afarwuah S (2008). Systematic review of the efficacy and effectiveness of complementary feeding interventions in developing countries. Matern Child Nutr4(Suppl 1):24-85. https://doi.org/10.1111/j.17408709.2007.00124.x

DOST-FNRI (2016). Philippine Nutrition Facts and Figures 2015: Anthropometric Survey. FNRI Bldg., DOST Compound, Gen. Santos Avenue, Bicutan, Taguig City, Metro Manila, Philippines.

Donowitz JR, Haque R, Kirkpatrick BD, Alam M, Lu M, Kabir M, Kakon SH, Zarin, Islam BZ, Afreen S, Musa A, Khan SS, Colgate ER, Carmolli MP, Ma JZ \& Petri WA Jr (2016). Small intestine bacterial overgrowth and environmental enteropathy in bangladeshi children. mBio 7(1):e02102-e2115. https:// doi.org/ 10.1128/mBio.02102-15.

Dos Reis JC, De Morais MB, Oliva CAG \& Fagundes-Neto U (2007). Breath hydrogen test in the diagnosis of environmental enteropathy in children living in an urban slum. Dig Dis Sci 52(5):1253-1258. https:// doi.org/10.1007/s10620-006-9288-9.

Eisenmann A, Amann A, Said M \& Ledochowski M (2008). Implementation and interpretation of hydrogen breath tests. $J$ Breath Res 2(4):046002. https://doi.org/10.1088/1752$7155 / 2 / 4 / 046002$.
Gilmartin AA \& Petri WAJ (2015). Exploring the role of environmental enteropathy in malnutrition, infant development and oral vaccine response. Philos Trans R Soc Lond B Biol Sci 370(1671). https://doi.org/10.1098/rstb.2014.0143.

Kahl L \& Hughes HK (Eds) (2017). The Harriet Lane Handbook E-Book. Elsevier Health Sciences, Philadelphia. From https://books.google.com. ph/books?id=hOWVDgAAQBAJ [Retrieved March 25 2021]

George CM, Oldja L, Biswas SK, Perin J, Lee GO, Ahmed S, Haque R, Sack RB, Parvin T, Azmi IJ, Bhuyian SI, Talukder KA \& Faruque AG (2015). Fecal markers of environmental enteropathy are associated with animal exposure and caregiver hygiene in Bangladesh. Am J Trop Med Hyg 93(2):269-275. https://doi. org/10.4269/ajtmh.14-0694.

Harper KM, Mutasa M, Prendergast AJ, Humphrey J \& Manges AR (2018). Environmental enteric dysfunction pathways and child stunting: A systematic review. PLoS Negl Trop Dis 12(1):e0006205. https://doi.org/10.1371/ journal.pntd.0006205.

Humphrey JH (2009). Child undernutrition, tropical enteropathy, toilets, and handwashing. The Lancet (London, England) 374(9694): 10321035. https://doi.org/10.1016/S01406736(09)60950-8.

Korpe PS \& Petri WA (2012). Environmental enteropathy: Critical implications of a poorly understood condition. Trends $\mathrm{Mol} \mathrm{Med}$ 18(6):328-336. https://doi.org/10.1016/j. molmed.2012.04.007.

Lin A, Arnold BF, Afreen S, Goto R, Huda TMN, Haque R, Raqib R, Unicomb L, Ahmed T, Colford J \& Luby SP (2013). Household environmental conditions are associated with enteropathy and impaired growth in rural Bangladesh. Am $J$ Trop Med Hyg 89(1):130-137. https://doi. org/10.4269/ajtmh.12-0629

Owino V, Ahmed T, Freemark M, Kelly P, Loy A, Manary M \& Loechl C (2016). Environmental enteric dysfunction and growth failure/stunting in global child health. Pediatrics 138(6):e20160641e20160641. https://doi.org/10.1542/ peds.2016-0641. 
Pereira SP, Khin-Maung U, Bolin TD, Duncombe VM, Nyunt-Nyunt-Wai, Myo-Khin \& Linklater JM (1991). A pattern of breath hydrogen excretion suggesting small bowel bacterial overgrowth in burmese village children. $J$ Pediatr Gastroenterol Nutr 13(1):32-38. https: / / doi.org/10.1097/00005176-19910700000006 .

Prendergast AJ \& Kelly P (2016). Interactions between intestinal pathogens, enteropathy and malnutrition in developing countries. Curr Opin Infect Dis 29(3):229-236. https://doi. org/10.1097 / QCO.0000000000000261.

Rezaie A, Buresi M, Lembo A, Lin H, Mccallum R, Rao S, Schmulson M, Valdovinos M, Zakko S \& Pimentel M (2017). Hydrogen and MethaneBased Breath Testing in Gastrointestinal Disorders: The North American Consensus. Am J Gastroenterol 112(5):775-784. https:// doi.org/10.1038/ajg.2017.46.

Soares Magalhães RJ, Salamat MS, Leonardo L, Gray DJ, Carabin $\mathrm{H}$, Halton $\mathrm{K}$, et al. (2015) Mapping the Risk of Soil-Transmitted Helminthic Infections in the Philippines. PLoS Negl Trop Dis 9(9):e0003915. https://doi. org/10.1371/journal.pntd.0003915

Torlesse H, Cronin A, Sebayang S \& Nandy R (2016). Determinants of stunting in Indonesian children: Evidence from a cross-sectional survey indicate a prominent role for the water, sanitation and hygiene sector in stunting reduction. BMC Public Health 16:669 https:// doi.org/10.1186/s12889-016-3339-8
Vonaesch P, Randremanana R, Gody JC, Collard JM, Giles-Vernick T, Doria M, Vigan-Womas I, Rubbo P, Etienne A, Andriatahirintsoa E, Kapel N, Brown E, Huus K, Duffy D, Finlay B, Hasan M, Hunald F, Robinson A, Manirakiza A, Wegener-Parfrey L, Vray M \& Sansonetti P (2018). Identifying the etiology and pathophysiology underlying stunting and environmental enteropathy: Study protocol of the AFRIBIOTA project. BMC Pediatrics 18(1):236. https://doi.org/10.1186/s12887018-1189-5.

Watanabe K \& Petri WA (2016). Environmental Enteropathy: Elusive but Significant Subclinical Abnormalities in Developing Countries. E BioMedicine 10:25-32. https:// doi.org/10.1016/j.ebiom.2016.07.030.

WHO (1994). Bench Aids for the diagnosis of intestinal parasites (1994). World Health Organization, Geneva.

WHO (1995). In: Physical Status: The Use and Interpretation of Anthropometry. From: https:/ / www.who.int/nutrition/publications/growth_ physical_status/en/ [Retrieved: January $\overline{5}$ 2020]. 